\title{
Impacts of highway runoff on metal contamination including Rare Earth Elements in a small urban watershed: case study of Bordeaux Metropole (SW France)
}

\author{
ANTOINE LERAT ${ }^{1}$, ALEXANDRA COYNEL ${ }^{1}$, JÖRG \\ SCHÄFER $^{1}$, ANTOINE MARACHE ${ }^{2}$, CLÉMENT PERETO ${ }^{1}$, \\ CÉCILE BOSSY ${ }^{1}$, MARION-JUSTINE CAPDEVILLE ${ }^{3}$ AND \\ DAMIEN GRANGER ${ }^{3}$ \\ ${ }^{1}$ Université de Bordeaux - UMR CNRS 5805 EPOC \\ ${ }^{2}$ Université de Bordeaux - UMR 5295 I2M \\ ${ }^{3}$ SUEZ - LyRE \\ Presenting Author: antoine.lerat@u-bordeaux.fr
}

High temporal resolution sampling of runoff (15 samples/4h) and river water (24 samples/24h) was performed during a major rainstorm $(41 \mathrm{~mm} / 4 \mathrm{~h})$ in the Bordeaux Metropole, after a dry and high vehicle-density period. Runoff was sampled at the outlet of one collector draining Northern Bordeaux Highway (NBH; $80,000-93,000$ vehicles/day) and river water in the downstream Jalle River. The studied metals, including priority and emergent (Rare Earth Elements - REEs) contaminants showed major temporal and spatial variations in the dissolved and particulate concentrations. Hierarchical cluster analyses distinguished metal groups, reflecting different: i) sources (i.e. automotive traffic: $\mathrm{Zn}-\mathrm{Cu}-\mathrm{Ce}$ and wastewater treatment plant: $\mathrm{Cd}-\mathrm{Ag}-\mathrm{Gd}$ ) and/or ii) processes (i.e. groundwater dilution by rainwater and sorption processes). The contribution of the particulate fraction to total metal fluxes was predominant in the NBH collector (except for $\mathrm{Sr}$ and $\mathrm{Mo}$ ) and highly variable in the Jalle River, where the highest particulate metal loads were due to the export of road dusts exported by the NBH collector. Metal fluxes from the NBH collector represented highly variable fractions of daily fluxes into the Gironde Estuary at the outlet of the Jalle River, depending on elements and partitioning. The resulting relative contributions ranged from: $5 \%(\mathrm{Sr})-40 \%(\mathrm{Cu})$ for dissolved phases and $30 \%$ (As) $-88 \%(\mathrm{Cu})$ for particulate phases. The first forty minutes of the event accounted for $65 \%$ of the suspended particulate matter flux (and associated particulate metals) exported by the NBH collector, whereas the respective water flux contribution was $35 \%$. This finding clearly demonstrates the importance of monitoring the first minutes of rainy events when establishing mass balances in urban systems. 